A 30-year-old woman underwent capsule endoscopy (Given ${ }^{\circledR}$ M2A, Given Imaging Ltd., Yoqneam, Israel) to investigate melena. Her medical history was significant for neurofibromatosis, portal and mesenteric vein thrombosis, portorenal shunt surgery, and antrectomy. On examination, her abdomen was slightly protuberant, with multiple surgical scars. A reducible, golf ball-sized, ventral hernia in the epigastric region was noted when performing a Valsalva maneuver. After swallowing the capsule, the patient left the clinic wearing a white T-shirt covering the capsule endoscopy (CE) belt pack. The next $7 \mathrm{~h}$ were uneventful, and no discomfort was experienced.

On reviewing of the video data, at $4 \mathrm{~h}$ and with the capsule in the distal small bowel, strong interference by white light was observed in numerous segments of the small bowel, making interpretation of the video image impossible. External light was shining through the bowel wall, creating a whiteout on screen (Figure $\mathbf{1}$ ). When capsule transitoccurred or therewas analtered orientation, light was seen to transilluminate from one side of the bowel wall (Figure 2) or was observed in the distance (Figure 3). The capsule locator program indicated a right upper quadrant position. The total duration of intermittent interference was approximately $40 \mathrm{~min}$. Capsule transit did not appear to be delayed, with normal peristalsis and no small-bowel dilation being observed [1]. In the last $2 \mathrm{~h}$ of recording, the CE image was not disturbed. On being questioned later, the patient recalled direct sunlight exposure corresponding to the time of the $\mathrm{CE}$ image whiteout.

To the best of our knowledge, this occurrence has not previously been reported in the medical literature. During colonoscopy or percutaneous endoscopic gastrostomy procedures, it is common to observe transabdominal illumination in the right lower quadrant or epigastrium, originating from the endoscope's light source.

\section{Sunlight Interference with Wireless Capsule Endoscopy}

Wireless CE depends on its own light source for image capture and recording. At present, there are no recommendations regarding shielding from strong ambient light during CE [2-3]. In normal circumstances, the $\mathrm{CE}$ belt pack provides an adequate light shield over the mid-abdominal and flank regions. However, over the upper abdomen, in patients with prior abdominal surgery, ventral hernia, or a thin abdominal wall, there is a risk of interference with CE from an extrinsic light source. We would therefore recommend that patients should avoid direct sunlight during CE or should wear light-resistant clothing for the duration of the test.

\section{S.-J. Tang, S. Zanati, E. Dubcenco,} M. Cirocco, G. Kandel, G. B. Haber, N. F. Marcon, P. Kortan

Center for Therapeutic Endoscopy and Endoscopic Oncology, St. Michael's Hospital, University of Toronto, Toronto, Ontario, Canada.

\section{References}

${ }^{1}$ Tang SJ, Zanati SA, Dubcenco E et al. Capsule endoscopy regional transit abnormality: a sign of underlying small bowel pathology. Gastrointest Endosc 2003; 58: 598-602

2 Ginsberg GG, Barkun AN, Bosco JJ et al. Wireless capsule endoscopy. Gastrointest Endosc 2002; 56: 621 - 624

${ }^{3}$ Given ${ }^{\circledR}$ diagnostic system. User's manual RAPID ${ }^{\circledR}$ Rev. 2.Yoqneam, Israel: Given Imaging, Ltd 2002

\section{Corresponding Author}

\section{P. Kortan, M.D.}

Center for Therapeutic Endoscopy and Endoscopic Oncology

Victoria Wing 16-048

St. Michael's Hospital

Toronto, Ontario M5B 1W8

Canada

Fax: +1-416-864-5619

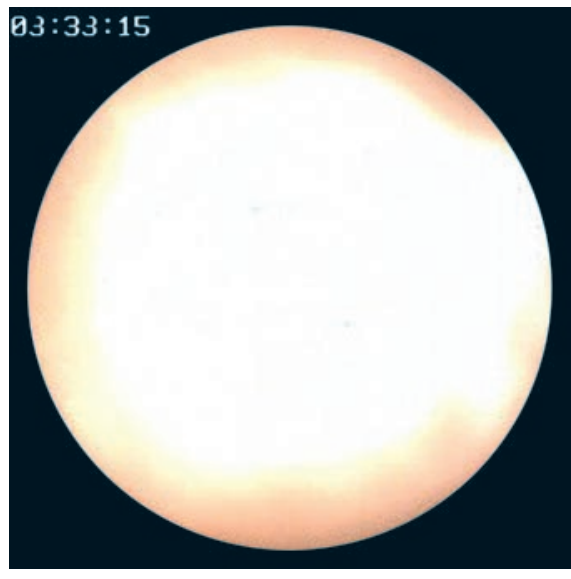

Figure 1 Capsule-endoscopic image, showing sunlight interfering with interpretation of the capsule video image.

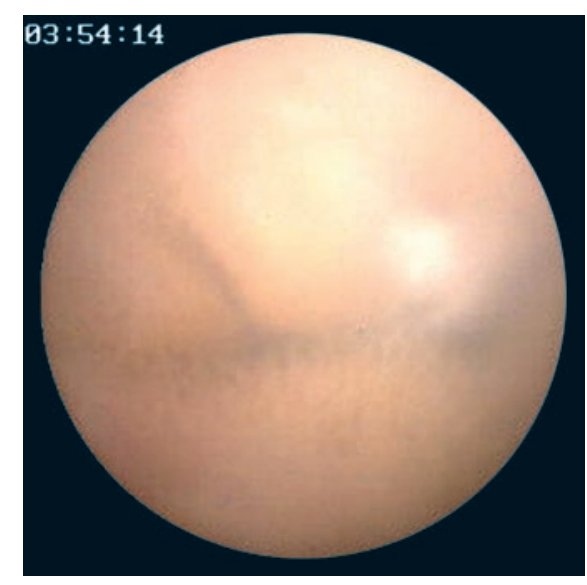

Figure 2 Sunlight shining through one side of the bowel wall.

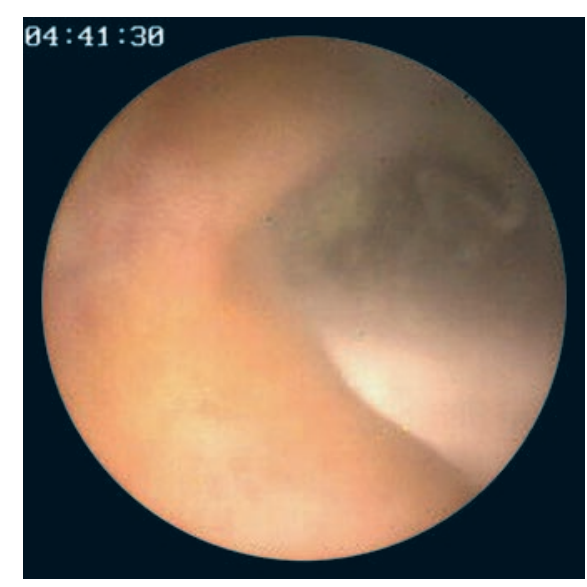

Figure 3 Sunlight shining in the distance. 